https://artnodes.uoc.edu

\title{
El temps circular: noves maneres de narrar l'experiència. La dramatúrgia acumulativa de La Conquesta del Pol Sud
}

\author{
Cristina Garde Cano \\ Universitat Autònoma de Barcelona \\ David Vidal Castell \\ Universitat Autònoma de Barcelona
}

Data d'entrega: octubre de 2021

Data d'acceptació: gener de 2022

Data de publicació: gener de 2022

\section{Cita recomendada}

Garde Cano, Cristina, Vidal Castell, David. 2022. «El temps circular: noves maneres de narrar I'experiència. La dramatúrgia acumulativa de La Conquesta del Pol Sud». En: Garcés, Marina (coord.). «Ecología de la imaginación». Artnodes, núm. 29. UOC. [Data de consulta: dd/mm/aa]. https://doi. org/10.7238/artnodes.v0i29.393042

Cls textos publicats en aquesta revista estan subjectes -si no s indica el contrari- a una llicència
SOMERIGHIS RESSERVED
de Reconeixement 4.0 Internacional de Creative Commons. La llicència completa es pot consultar
a https://creativecommons. org/licenses/by/4.0/deed.es

\section{Resum}

L'article examina de manera crítica la temporalitat pròpia de la narració capitalista occidental, caracteritzada per l'oposició entre passat, present i futur, i que Heidegger va anomenar «temps vulgar»: lineal, unívoc, segmentat, veloç i accelerat. En tant que éssers simbòlics, conformats individualment i col-lectiva per narracions, trobem cabdal proposar una temporalitat alternativa -en part d'inspiració oriental, en part provinent de la filosofia i la crítica de la cultura-, que entén el temps com un procés circular, i que ens dota de nous recursos per narrar l'experiència, generar imaginaris i construir-nos des de l'empatia, l'alteritat 0 la transcendència en les nostres comunitats. En una segona part, l'article esdevé un estudi del cas exemplar: presentem una anàlisi del mètode de treball de La Conquesta del Pol Sud, concretament de la seva trilogia Nadia/Claudia/Raphaëlle, feta des de la discussió conceptual prèvia. Després d'analitzar els seus muntatges i de mantenir-hi diverses entrevistes, la proposta que presentem es desplega en tres plecs: com percebem el temps, com 
narrem l'experiència i com fem servir el llenguatge. Considerem que les indústries discursives, i dins d'aquestes el periodisme, com a disciplina simbòlica que vehicula relats amb narracions, s'han de preguntar per la idea de temps que imposen i quines implicacions té en els imaginaris que habiten les comunitats. Com podem desmuntar aquest temps, cada vegada més veloç? Com podem imaginar, amb una altra temporalitat, noves narracions?

\title{
Paraules clau
}

temps; narració; experiència; imaginaris; La Conquesta del Pol Sud; teatre documental

\section{Circular time: new ways to narrate experience. The cumulative dramaturgy of La Conquesta del Pol Sud}

\begin{abstract}
This article will critically examine the temporality native to western capitalist narration, characterized by the opposition between past, present, and future, and that which Heidegger terms "vulgar time": linear, unique, segmented, rapid and accelerated. In terms of symbolic beings, made up individually and collectively of narrations, we find that it is key to propose an alternative temporality - partly inspired by the east, partly coming from the philosophy and critique of culture - which interprets time as a circular process and affords us new resources for narrating experience, generating imaginaries and constructing us from empathy, otherness and transcendence in our communities. In its second part, the article constitutes a case study: we present an analysis of the working method of La Conquesta del Pol Sud, specifically of its trilogy Nadia/Claudia/Raphaëlle, product of the prior conceptual discussion. Having analyzed its montages and holding several interviews, the proposal we present is developed across three documents: how we perceive time, how we narrate experience and how we use language. We consider that discursive industries, including journalism in the sense of a symbolic discipline that conveys stories via narration, should be contemplated for the idea of time that they impose and what implications this has on the imaginaries in which communities reside. How can we dismantle this time, which grows ever faster? How can we imagine, with another temporality, new narrations?
\end{abstract}

\section{Keywords}

time; narration; experience; imaginaries; La Conquesta del Pol Sud; documentary theatre

\section{Presentació: el problema de la temporalitat com a dispositiu}

L'ésser humà, ésser simbòlic i narratiu al qual la immediatesa és negada, necessita incardinar la seva experiència per comprendre-la. Per mitjà de la narració, aquesta experiència s'incardina en un temps i en un espai, o si volem dir-ho d'una manera més abstracta, en una temporalitat, sigui quina sigui, i en una espacialitat, sigui quina sigui.

Aquesta temporalitat, a la tradició occidental, ha estat vinculada a la tensió entre eternitat i contingència, que ja és a la base del pensament judeocristià. Des de molt antic, però més específicament $a$ partir del desenvolupament de la indústria i de la cultura els darrers dos segles, aquesta temporalitat ha estat útil perquè l'ésser humà doni forma a la seva vivència i la converteixi en experiència narrada, col·lectiva 0 individual (Duch i Chillón 2012). Aquesta temporalitat, que Heidegger (1927/1986) va anomenar «temps vulgar», és lineal, unívoca, avança en tant que existeix un subjecte, que es col·loca en el centre i segmenta la seva vivència en esdeveniments, que són posats en escena, que s'oposen i trenquen amb els esdeveniments anteriors.

Aquesta temporalitat, així entesa, no deixa de ser un dispositiu que ens ajuda a copsar i alhora a conformar l'experiència, narrativament, des d'un ordre i des d'un sentit, tal com ho va fer la perspectiva en les arts visuals i, específicament, en la pintura. També com a dispositiu de sentit, la temporalitat lineal col·loca el subjecte en el centre de la narració i fa girar al seu voltant l'experiència de la vida, com va fer la perspectiva, desenvolupada, com sabem, en una època de rampant antropocentrisme.

A més, aquesta noció (i praxi) de la temporalitat ha completat a les darreres dècades tres girs de sentit que compliquen encara més la percepció de l'experiència: primer, aquesta concepció assimila, a causa de la linealitat, temps amb moviment; en segon lloc, equipara moviment amb velocitat; i, finalment, identifica velocitat amb acceleració. 


\section{artnodes}

https://artnodes.uoc.edu

El temps circular: noves maneres de narrar l'experiència. La dramatúrgia acumulativa de La Conquesta del Pol Sud

Per tant, aquest «temps vulgar» que ens permetia narrar la vivència humana ha desembocat en una acceleració sense precedents, que és a la base del capitalisme, i tal vegada ho és perquè el capitalisme neix en aquest paradigma cultural, encarnat en la indústria del discurs, periodístic, literari 0 artístic.

Aquesta temporalitat, doncs, s'ha pervertit de tal manera que l'activitat narrativa, que dota de sentit la nostra vida (Ricoeur 1985/1996, Lynch 1987/2006), es desenvolupa dins d'uns paràmetres que limiten la forma com ens podem construir individualment i col-lectiva. Per això, creiem que cal explorar nous imaginaris, i és l'objectiu d'aquest article fer-ho, que ens ajudin a explicar el temps d'una altra manera i ens dotin de noves formes de narrar l'experiència i de construir-nos des de l'empatia, l'alteritat o la transcendència, tots trets fonamentals per a una «vida vivible» (Garcés 2015).

\subsection{La Conquesta del Pol Sud, documentalitat i evocació}

La Conquesta del Pol Sud és una companyia de teatre fundada el 2010 a Barcelona, per Carles Fernández Giua i Eugenio Szwarcer. Des de I'inici, l'interès de la companyia se centra en la dramatúrgia contemporània i experimenta amb textos que articulen contingut social i nous llenguatges escènics. Aquest interès els apropa a la documentalitat i al treball etnogràfic com a matèria teatral, en una exploració de llenguatges en què s'entrecreuen el periodisme, el cinema, el teatre i l'evocació literària. Dels seus diversos projectes, ens interessa, per tal de posar a prova la nostra proposta, el que ha assolit més reconeixement, ${ }^{1}$ la trilogia Nadia/Claudia/Raphaëlle, que ells qualifiquen de «documentals escènics». ${ }^{2}$

L'objectiu de la trilogia és explicar com s'interrelacionen les vides de tres dones amb «les vides de tothom», tal com ells mateixos expliquen al web: «Estendre ponts entre l'experiència individual i la història col·lectiva». ${ }^{3}$ També es pregunten per la vigència (i per la construcció) de conceptes fonamentals, com la memòria i, sobretot, la identitat, que es presenta inestable en les seves dramatúrgies. Les tres dones protagonistes senten que són algú diferent de qui els altres diuen.

En el primer cas, Nadia Ghulam és una dona d'origen afganès que, de nena i durant el règim dels talibans, es va haver de fer passar per un nen per mantenir la família. Claudia és la història de la primera dona a l'Argentina que renuncia a la seva família d'adopció, Claudia Poblete, després de descobrir que la seva família biològica havia estat torturada i assassinada per la dictadura de Videla. Finalment, RaphaëIle narra la vida d'una jove transsexual francesa, Raphaëlle Pérez, que es qüestiona què vol dir la identitat de gènere i sexual, i les violències simbòliques que pateix.

\subsection{Metodologia i preguntes: els tres plecs del temps narrat}

Aquest text desenvolupa inicialment un estat de la qüestió en què es discuteix el concepte de temporalitat occidental lineal i els seus efectes en la construcció de les narracions contemporànies. Això ho fem tot presentant, alternativament, aportacions de la filosofia i de la sociologia de la cultura, sobretot d'autores i autors que sovint no han estat centrals en aquesta discussió fins avui. El text explora una alternativa al concepte hegemònic de temporalitat de la cultura occidental, deutor d'Aristòtil, per trobar-hi intuïcions sobre com entenem i practiquem la narració i les seves consubstancials praxis cognitives les persones que es dediquen al periodisme, la literatura o les arts.

En una segona part, l'article esdevé un estudi del cas exemplar: presentem una anàlisi del mètode de treball de La Conquesta del Pol Sud, concretament de la seva trilogia Nadia/Claudia/Raphaëlle. La tria respon al fet que la companyia i els seus muntatges manifesten dues característiques bàsiques per a la nostra exploració teòrica: duen a terme un treball de construcció de la narració des de la documentalitat i, per tant, s'enfronten al problema de la temporalitat viscuda que esdevé temps del relat, fent servir l'expressió de Ricoeur; i ho fan des de l'experimentació libèrrima del llenguatge dramatúrgic, que intersecciona amb altres praxis narratives - literàries, audiovisuals, periodístiques. Després d'analitzar-ne els muntatges i de mantenir-hi diverses entrevistes, la proposta que presentem es desplega en tres plecs: com percebem el temps (plec 1), com narrem l'experiència (plec 2) i com fem servir el llenguatge (plec 3). Les entrevistes s'han dut a terme amb els membres fundadors i responsables de la companyia, Carles Fernández Giua i Eugenio Szwarcer.

\section{Diagnosi: 'temps sense procés', velocitat i acceleració}

Malgrat que hi ha autors, com Fukuyama (1992), que es feliciten de la «fi de la història», com ha explicat Vidal Castell (2005), la sospita que vivim un temps sense procés tenalla el pensament d'0ccident des de fa segle i mig. Rimbaud, Mallarmé, Nietzsche, Kraus, Hofmannstal, Zweig, Mauthner, Musil, Steiner, Canetti, Beckett, Joyce i tants altres autors

\footnotetext{
1. La trilogia s'ha representat internacionalment a desenes d'escenaris d'Europa i Amèrica; al nostre país, ha estat un èxit sostingut (encara es representa) de crítica i públic, ha presentat muntatges al Festival Grec de Barcelona (2014 i 2016), al CCCB i al Teatre Nacional (2016, 2017 i 2020), i el seu llenguatge dramatúrgic ha estat distingit amb premis importants, com el premi de la Crítica Serra d'Or. Es poden veure tots tres muntatges encara ara, de gira per Catalunya.

2. La companyia ha creat altres muntatges sota la mateixa concepció, o molt similar, per exemple Suburbana, una creació audiovisual basada en la figura de Najim, un jove immigrant que es dedica a la recollida de cartró i metall, que és seguit durant setmanes, càmera en mà, per l'equip de la companyia, sempre interessat a veure com el pla individual s'interseca en el col-lectiu. https://www.laconquesta.com/proyectos/trilogia, data de consulta 10/10/2021.

3. https://www.laconquesta.com/proyectos/trilogia, data de cconsulta 10/10/2021.
} 


\section{artnodes}

https://artnodes.uoc.edu

El temps circular: noves maneres de narrar l'experiència. La dramatúrgia acumulativa de La Conquesta del Pol Sud

han volgut explicar aquesta inquietud com el símptoma d'una concatenació de crisis que semblen no tenir aturador: la crisi de la paraula, de les ideologies, de les identitats, de les pedagogies, de l'economia, del periodisme...

Creiem que aquesta certesa beu d'una qüestió encara més fonamental: què és el temps, i per què 0 ccident l'ha convertit en el ferment del seu esdevenir? El dubte també el té el filòsof i sinòleg François Jullien (2005): «[...] ¿había que pensar[se] el tiempo? No se trata, entiéndase bien la pregunta, de cómo pensar el tiempo —al respecto, la filosofía, no ha dejado de disertar-, sino de que, más radicalmente, ¿había necesidad de un concepto de ‘tiempo'? ¿Y para qué?» (Jullien 2005, 9).

La idea de temps que a 0ccident hem acceptat com a fundacional, des de la Física d'Aristòtil i la seva trajectòria del mòbil, es representa com una fletxa que avança en línia recta. On la fletxa es dispara és el passat. On la fletxa es dirigeix és el futur. Enmig va sent el present, la vida, que se'ns escapa de manera irreversible. Nosaltres som en la trajectòria de la fletxa. Segons la lògica aristotèlica, per tant, el temps no es pot copsar sense el moviment. De tant que hem interioritzat aquest principi, n'hem acabat fent metonímia: confonem temps i moviment. En definitiva, el temps, diu Jullien, com una «magnitud figurada por una línea divisible y continua» (Jullien 2005, 4).

A més, a l'Occident capitalista, explica Paul Virilio (1977/2006), el temps lineal, homogeni i segmentat s'imposa mitjançant una interpretació perversa: fa dècades que, per dominar el relat, emprem el concepte de velocitat, més concretament, l'acceleració, per anomenar allò que, de fet, és el moviment. Per això, el model capitalista vol que produïm com més ràpid millor. El materialisme encara rebla el clau quan diu que «el temps és diners» 0, amb les ulleres marxistes, que «el temps és treball.» Virilio també recorda que, a les democràcies industrials, el concepte de velocitat -i d'acceleració- està íntimament lligat a una violència atàvica que les alimenta, un «asalto permanente del mundo y a través de él como un asalto a la naturaleza del hombre»(Virilio 2006, 63).

Podem afirmar, per tant, que des de la perspectiva del temps occidental, el capitalisme posseeix el present continu i ens impedeix construir cap possibilitat, perquè ens obliga a concebre el passat $i$ el futur com a antagònics, i no com una confluència d'energies en transformació en l'aquí $i$ ara. En el capitalisme de la vigilància, l'etern scroll a les xarxes socials és un bon exemple d'això que intentem explicar. «The time is out of joint», escriu Shakespeare a Hamlet. Ens ho recorda Jacques Derrida, que argumenta que «el tiempo está fuera de quicio, está deportado, fuera de sí, desajustado» (Derrida 1995, 31). Aquest paradigma del temps sense procés ho impregna tot, fins i tot els corrents crítics al sistema capitalista.

Entre els autors crítics que defensen que davant de l'acceleració del capitalisme ens cal decréixer, hi ha molts pensadors que hi han reflexionat des de la teoria econòmica, i d'altres que provenen de l'antropologia cultural, com Lluís Duch o Remedios Zafra. Duch (2019) analitza de manera precisa els riscos d'aquest temps sense procés i proposa «el sosiego». I Zafra adverteix que són «los propios trabajadores precarios y autoexplotados los que se invitan y proponen sin descanso, neutralizando sus tiempos bajo la impresión de que es uno mismo el que se autosomete, mientras también autoexplota el colectivo» (Zafra 2021, 39).

A l'altra banda, entre els autors crítics que es volen apropiar de l'acceleració hi ha, per exemple, Alex Williams i Nick Srnicek, que afirmen que l'acceleració pot ser «essencial», si és entesa com a «navegacional»: «Si la izquierda política quiere asegurarse un futuro, deberá ser uno en el que adopte al máximo esta tendencia acceleracionista reprimida» $(2019,39)$. En aquest mateix sentit, s'expressen Armen Avanessian i Mauro Reis (2019).

Tanmateix, les teories acceleracionistes no són compartides de manera fervorosa per tots els autors pròxims al ciberpunk. Franco «Bifo» Berardi afirma: «¿Es la aceleración una condición para el colapso final del poder capitalista? Difícil creerlo: la aceleración es la forma esencial del crecimiento capitalista» (2019a, 69). Així mateix, Mark Fisher (2018), tot i que no renuncia en absolut a l'acceleracionisme, advertirà que el futur sovint es conjura com un exercici d'evasió davant de la lògica aniquiladora del capitalisme tardà, davant del que ell anomena «realisme capitalista».

L'autor afirma que «el poder del realismo capitalista deriva parcialmente de la forma en la que el capitalismo subsume y consume todas las historias previas» (Fisher 2018, 25). I apunta: «Solo puede intentarse un ataque serio al realismo capitalista si se lo exhibe como incoherente 0 indefendible; en otras palabras, si el ostensible 'realismo' del capitalismo muestra ser todo lo contrario de lo que dice» (Fisher 2018, 42). Tanmateix, la reflexió idealista d'aquests autors crítics no té prou capacitat per afeblir el present continu del capitalisme, perquè, malgrat que evidencien les contradiccions del sistema, no són capaços d'intervenir en l'aquí $i$ ara.

Així, el temps continua tenint, tal com afirma Jullien, la rigidesa d'un lloc comú que travessa totes les disciplines de la nostra tradició: en la física, per mesurar el moviment dels cossos en l'espai; en la filosofia, per oposar l'essència finita del subjecte contra l'eternitat de Déu 0 de l'univers; en la gramàtica, en la conjugació dels verbs; i en l'antropologia -ens interessa sobretot aquesta perspectiva-, com a temps viscut i temps narrat, com a temps de l'acció i temps del llenguatge.

D'aquesta manera, Paul Ricoeur considera «la narración como el guardián del tiempo, en la medida en que no existiría el tiempo pensado si no fuera narrado» $(1996 / 1985,991)$. «Todo lo que se cuenta sucede en el tiempo, arraiga en el mismo, se desarrolla temporalmente; y lo que se desarrolla en el tiempo puede narrarse», abunda en un article posterior $(2000,190)$. Enrique Lynch (1987/2006) resumeix la naturalesa de la narració amb la imatge del «tiempo atado».

I Lluís Duch afirma que, «per a l'ésser humà, l'espai i el temps, allò que Merleau-Ponty designava amb l'expressió 'espai i temps 


\section{artnodes}

https://artnodes.uoc.edu

El temps circular: noves maneres de narrar l'experiència. La dramatúrgia acumulativa de La Conquesta del Pol Sud

antropològics', constitueixen una matriu interpretativa engendradora de significacions i possibilitats, somnis i desigs, angoixes i foscors, la qual emmarca i determina tot allò que és capaç de comunicar l'ésser humà [...]» $(2002,32)$. Tanmateix, Duch $(2019,148)$ també apunta a una «fractura generalitzada» dels processos de transmissió i aprenentatge, i assenyala directament els mass-media, que ell situa dins d'una estructura d'acollida, ${ }^{4}$ la comediació, que permet a les comunitats transferir el seu substrat cultural.

De fet, tots els autors citats tenen clar que els mass-media, les plataformes i les xarxes socials són els grans altaveus mitjançant els quals s'inocula aquest temps accelerat. Els periodistes conscients ${ }^{5}$ també reconeixen aquesta obvietat, i la manera com la combaten s'assembla força a aquestes dues postures antagòniques que hem esmentat. Mentre que hi ha uns neoapocalíptics, ${ }^{6}$ que proposen una alternativa en l'anomenat periodisme lent $\mathrm{i}$ en les lliçons del vell nou periodisme, hi ha uns neointegrats, que lluiten per subvertir les lògiques algorísmiques de les plataformes i s'apropien amb entusiasme dels espais de visibilitat del capitalisme accelerat. En cap cas, però, no renuncien al paradigma hegemònic del temps vulgar.
És per això que creiem que les indústries discursives, i dins d'aquestes el periodisme, com a disciplina simbòlica que vehicula relats amb narracions, s'han de preguntar per la idea de temps que imposen i quines implicacions té en els imaginaris que habiten les comunitats. Com podem desmuntar aquest temps, cada vegada més veloç? Com podem imaginar, amb una altra temporalitat, noves narracions?

\section{Anàlisi d'un cas exemplar: una proposta per narrar un temps circular. Resultats i discussió}

De l'estat de la qüestió que acabem de completar, i de les preguntes que ens fem en aquest article, se'n deriva un guió per a les entrevistes que hem fet amb els dos membres fundadors de la companyia La Conquesta del Pol Sud, Carles Fernández Giua i Eugenio Szwarcer. ${ }^{7}$ Tal com hem avançat en l'apartat de metodologia, hem estructurat les preguntes en tres plecs, que desenvolupen la reflexió sobre la temporalitat, i que s'enfoquen en com percebem el temps (plec 1), com narrem l'experiència (plec 2) i com fem servir el llenguatge (plec 3).

\begin{tabular}{|c|c|}
\hline $\begin{array}{c}\text { PLEC 1: } \\
\text { COM PERCEBEM EL TEMPS? }\end{array}$ & $\begin{array}{l}\text { A les vostres obres, enteneu el temps com un procés en evolució? És així? Heu fet aquesta } \\
\text { reflexió sobre la temporalitat? } \\
\text { Concebeu el subjecte com a ego, o més aviat com a dipositari d'una història que cal transmetre, } \\
\text { entesa aquesta història com una potencial revelació que transcendeix el personatge? } \\
\text { És conscient que hi hagi en les tres obres la necessitat d'explicar com una certa visió del món } \\
\text { violenta els qui intenten construir-ne una altra d'alternativa? }\end{array}$ \\
\hline $\begin{array}{c}\text { PLEC 2: } \\
\text { COM NARREM } \\
\text { L'EXPERIENCIA? }\end{array}$ & $\begin{array}{l}\text { Concebeu l'obra com una acció que ha de caminar cap a una transformació col·lectiva? Per què? } \\
\text { En el canvi que narreu en totes tres històries, hi ha trencaments bruscos, o no? Per què? } \\
\text { Observem que en les obres de la trilogia, l'escenografia no es construeix en una successió } \\
\text { d'escenes, sinó més aviat en un cúmul articulat de circumstàncies que desemboquen en la } \\
\text { construcció de moments de comunió/connexió amb els altres. Per què és així? } \\
\text { En la trilogia, observem que les protagonistes no es construeixen al voltant del que són (o de la } \\
\text { presència), sinó per mitjà de la seva capacitat de fer en el moment adequat. És una cosa que heu } \\
\text { tingut present? }\end{array}$ \\
\hline $\begin{array}{c}\text { PLEC 3: } \\
\text { COM FEM SERVIR EL } \\
\text { LLENGUATGE? }\end{array}$ & Per quin motiu barregeu passat, present i futur en el llenguatge de la vostra dramatúrgia? \\
\hline
\end{tabular}

Taula 1. Qüestionari de l'entrevista en tres plecs Font: elaboració pròpia

4. Duch (2019) explica que les comunitats humanes transmeten el seu substrat cultural en quatre grans àmbits d'acollida: la codescendència, que representa l'àmbit de la família; la coresidència, que representa el grup social; la cotrascendència, que representa els espais en els quals es construeix l'espiritualitat, i la comediació, en què hi ha els mass-media i tota la resta d'institucions mediàtiques, com les plataformes, les xarxes socials, el cinema, etc.

5. Héctor Borrat, a la seva tesi, mesura la professionalitat dels periodistes basant-se en aquesta gradació en la consciència. Paradoxalment, afirma, els periodistes que són més conscients dels poders polítics i econòmics que sotmeten els mitjans de comunicació tenen menys oportunitats de prosperar en l'organització d'aquests mitjans.

6. Prenem la classificació que fa Umberto Eco (1984) dels dos tipus d'intel·lectuals que es confronten en la cultura de masses i l'actualitzem per analitzar el context del capitalisme de plataforma.

7. Les entrevistes es van fer els dies 11 i 12 d'octubre, seguint un guió lliurat prèviament als dramaturgs, en format online, i van ser enregistrades. En l'apartat 3 , fem un resum i una discussió de les respostes, en relació amb els objectius presentats en aquest article, i un cop destilllades pels autors. Conservem les gravacions íntegres. 


\subsection{Plec 1: procés, correlacions i immanència}

Els muntatges de la trilogia de La Conquesta del Pol Sud, s'alimenten d'una temporalitat alternativa. Ho fan de manera intuïtiva, sí, però recullen imaginaris al voltant del procés, el canvi, la immanència 0 les correlacions, tal com ho fa Jullien a partir de la tradició oriental. «Malgrat tot, encara que dinamitem el temps vint vegades, acabem creant un producte que s'exhibeix, en una unitat i un format», es lamenta Eugenio Szwarcer. Tant Szwarcer com Carles Fernández Giua senten una preocupació per la utilitat dels seus muntatges. «Tots els inputs que miren de fer-nos entendre el món són mediats. I així és molt difícil conèixer de primera mà alguna cosa. Sentim una desconfiança pels mitjans i, per això, vam pensar que ens volíem acostar a les fonts testimonials», reflexiona Fernández Giua, que assenyala que, al capdavall, «tota història, tota memòria, és narració».

Per això, consideren el temps de l'obra com un procés en constant evolució, tot i que admeten que no han trobat la manera de fer-ho de «manera més sistemàtica». «Hi ha obres a les quals he de tornar cada cert temps, i em pregunto si encara penso i sento allò que algun dia em vaig representar. I hi ha obres que són més com capítols tancats de la vida d'algú que van cristal.litzar», ${ }^{8}$ resumeix Szwarcer. Tanmateix, sí que s'adonen que el procés segueix viu «espiritualment» en les tres protagonistes. «Hi ha coses, intencions, pauses, imaginaris que canvien», assenyalen. Fins i tot, ha arribat un moment en què a algunes de les protagonistes se'ls desperta la necessitat d'explicar altres vivències, com li ha passat a Nadia Ghulam. Szwarcer també recorda «alguns processos espontanis» que exemplifiquen aquesta necessitat, com quan van dur Nadia a Berlín (Alemanya) i Ghulam va interrompre el text original en una de les representacions, i va explicar que aquell matí havia visitat la ciutat i havia vist imatges del Berlín bombardejat que li van recordar el Kabul de la seva infància.

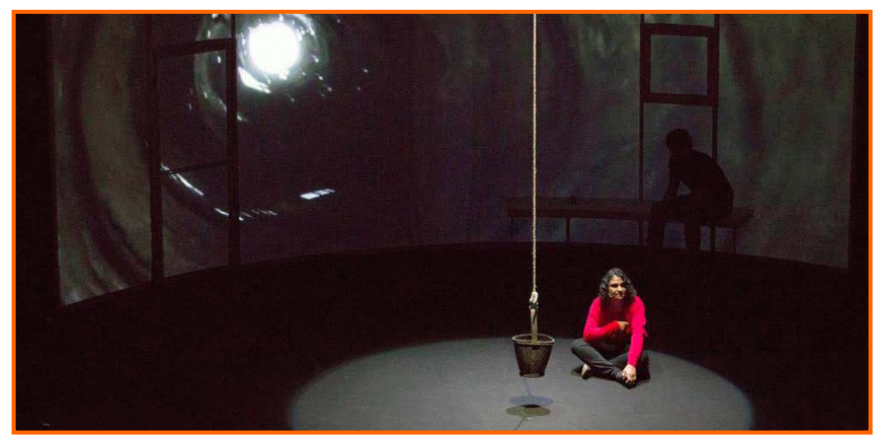

Figura 1. Nadia Ghulam recorda la seva infantesa a Kabul (2019) Font: https://www.laconquesta.com/proyectos/trilogia-nadia

«Part del nostre mètode és aquest viatge entre allò individual i allò col·lectiu», argumenta Szwarcer sobre la construcció del subjecte dalt de l'escenari, que no és en cap cas un ego, sinó un dipositari d'una història col-lectiva que cal transmetre, que és immanent. «Si no, només hi hauria el morbo de mostrar la vida d'una persona, que pot ser fascinant, però que faria que te n'anessis absolutament indiferent a casa», amplia. En aquesta voluntat ressona, en certa manera, el que proposa Franco «Bifo» Berardi (2019b), quan prova d'alliberar d'aquest «temps vulgar» accelerat aquesta existència nostra que no sap com narrar-se. Ho fa renunciant-hi directament i, per contra, fa servir conceptes com potència, energia, poder, possibilitat, contingut, forma, enigma o consciència.

De fet, en la trilogia, la concepció de l'individu, asseguren ambdós dramaturgs, parteix d'una voluntat conscient de «revolució» que s'acosta a la potència mobilitzadora que planteja «Bifo» amb el terme «futurabilitat». Aquesta «revolució» fa palesa, per als espectadors, la violència amb què el discurs hegemònic s'imposa sobre la narració alternativa que les protagonistes intenten crear. «Les persones amb què vam triar treballar fan una revolució individual, perquè s'enfronten a categories establertes, han de trencar amb una ficció que s'havia construït al voltant seu», afirma Fernández Giua.

Per a ells, el cas de la Claudia Poblete és el que mostra de manera més evident com la narració imposada sobre els infants robats de la dictadura argentina culmina amb el gran esdeveniment dels judicis. En canvi, l'experiència d'aquestes persones (i de la Claudia) va ser la d'un procés lent i feixuc de reconeixement de la nova identitat, que no es podia simplificar amb segments d'una línia temporal en què destacava la gran fita mediàtica. Des de la percepció d'un temps continu, un procés que continua encara avui per a les seves protagonistes, la companyia ha d'assumir aquest repte de narrar l'experiència que la cultura dominant ens fa veure com a episòdica, seqüencial.

\subsection{Plec 2: canvi, circumstància i acumulació}

La continuïtat amb què La Conquesta del Pol Sud percep el temps de les protagonistes a la trilogia s'enfronta, dèiem, a un repte de dramatúrgia: com trobar la forma escènica que mostri les transicions de la identitat sense salts bruscos. "Claudia tenia una identitat imposada -explica Fernández Giua- que ella mai s'havia qüestionat. A Raphaëlle, hi ha un moment en què el sistema sanitari li imposa una narració de manera molt violenta.» El mètode i el camí per generar aquesta continuïtat en el procés i evitar la mera successió d'episodis és, un cop més, el de l'etnografia, un procés de comunicació participativa que s'assembla al que practiquen Catalina Gayà i Laia Seró (2021) a l'entorn dels museus.

En les obres de La Conquesta, no hi ha una successió d'escenes artificialment creades, sinó que més aviat els públics connecten perquè travessen plegats un cúmul de situacions que generen un moment de connexió o comunió amb les protagonistes. Es trenca la quarta paret, tal com fa Roger Bernat ${ }^{9}$ en les seves obres. «Per poder treballar la

8. Desenvolupem aquest concepte, cristal/litzar, més endavant, ja que té a veure amb la reflexió sobre temporalitat i les formes de narrar.

9. Roger Bernat. «Com trenquem la quarta paret», entrevistat per Albert Lladó, Escola de pensament, Teatre Lliure, 28 de juny, 2021, vídeo, 1:20:46, https://www.youtube.com/watch?v=gFsJXzsxAEc. 
diversitat de capes de significat que se succeeixen al mateix temps, cal una estructura ben constrüda -diu Szwarcer-. Però, busquem el moment màgic. I l'espectador sent una continuïtat, això sí.»

Els dos membres de la companyia estan d'acord en el fet que el que generen són «moments, empaties», un fluid de situacions que s'acumulen i es mouen endavant i enrere. No és casual que el llenguatge escènic de La Conquesta funcioni «per superposicions de capes de sentit», per «plecs del temps i del relat sobre ell mateix», per circularitats, «per acumulació», com el patchwork que cus i descús, com una moderna Penèlop, Claudia Poblete. La manera com cedeixen el control del discurs a les protagonistes és molt significatiu; un discurs entès com una opera aperta. I, de fet, ens aproxima a l'imaginari de les arts visuals contemporànies, que, en part, han decidit abandonar l'obra completa, i opten per altres experiències de connexió amb els públics, en allò que coneixem com a arts performatives.

Així, els muntatges de la trilogia arriben tots, de manera molt laboriosa i colllaborativa, a un text final: "No és un text de sortida que escrivim nosaltres, és un text d'arribada: la tria d'aquestes paraules, la composició del text, és un exercici de llibertat molt gran d'aquestes persones. Ens interessen persones lliures que decideixen transmetre la seva experiència, que trien la manera de fer-ho i que són molt conscients de com està arribant. Aquesta circularitat, aquest tornar-hi com a mètode és l'exercici sanador."

Al voltant de les circularitats, precisament, convé vincular aquesta reflexió amb la de Derrida (1995), que fa una impugnació al temps sense procés, quan proposa una teoria crítica -l'hauntologia- per desenterrar les traces, els espectres, d'ideologia marxista que encara subjauen en el present continu capitalista. Derrida afirma que els espectres són com les petjades a la neu; anticipen allò que ha de succeir, embruixen l'atmosfera, assetgen el temps lineal; són latents i històrics. El filòsof explica que podem convocar aquesta absència mitjançant un treball del dol, que ens ha de permetre donar sentit a les restes, localitzar-ne les petjades i identificar-les, reconèixer-ne les veus i entendre de quina manera han transformat l'aquí $i$ ara.

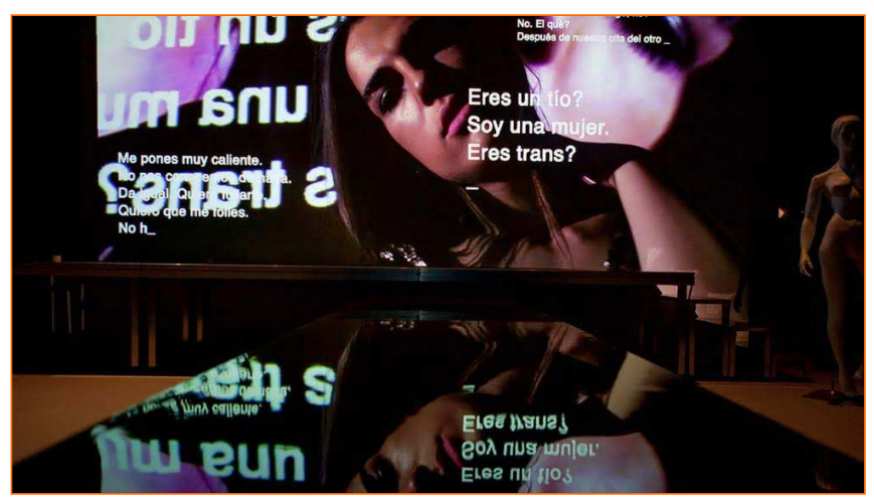

Figura 2. Raphaëlle pensa la seva identitat sexual contra el discurs oficial (2019) Font: https://www.laconquesta.com/proyectos/trilogia-raphaelle
En aquest sentit, Szwarcer oposa aquest treball de convocatòria acumulada de tots els temps al concepte de cristal-lització: «L'experiència traumàtica que van viure, per a elles, estava cristal-litzada, estava tancada. Nosaltres els donem eines perquè ho revisitin i puguin empoderar-se en el relat». Així, la dramatúrgia que creen es fa «a la mida de la persona, que no és una actriu professional», i ha de ser còmoda perquè ella la transiti; per això, probablement, no s'hi veu la seqüencialitat abrupta de les escenes convencionals.

\subsection{Plec 3: la transició, les paraules ballen entre elles.}

Els fundadors de la companyia ho tenen ben clar: «En els nostres muntatges, el present, el passat i el futur estan junts en una sola persona. Això és una cosa volguda. Segueixes una narració, però tornes enrere i et projectes en el futur», diu Fernández Giua. Claudia n'és un exemple molt clar: a l'escena final, es representa el passat, ella quan era petita; el present, ella, a l'escenari; i el futur, la seva filla. També és així en el cas de Raphaëlle: en el monòleg final, ella torna a connectar amb el nen que va ser i narra «la violència de la societat, de la mirada» i diu: «Por esa niña que fui sin saberlo». Finalment, a Nadia, Nadia Ghulam es fon a l'escenari amb la imatge d'ella quan tenia set anys, abans de quedar ferida pel bombardeig.

Però, com és possible resseguir aquests rastres de les presències? Per mitjà de l'hauntologia, Derrida proposa fer gairebé un exercici de sociologia arqueològica 0 d'antropologia cultural. Per interpretar els espectres, diu Derrida, ens cal dialogar-hi, conjurar-se, comprometre's, saber des d'on els convoquem i quina experiència ens hi vincula. El filòsof explica que l'aquí i ara, en la concepció del «temps vulgar», està desencaixada, perquè, com diu Heidegger, fa de juntura entre el passat i el futur mitjançant la presència, que en la cultura dels mass-media és fantasmagòrica, simulada i retransmesa mil vegades. Per això, Derrida es pregunta si aquesta absència no pot mantenir unida la disparitat (passat i futur) com no aconsegueix fer-ho la presència. Desenterrar aquests espectres és una oportunitat per a allò que està per venir.

Al capdavall, Derrida (1972/2005) constata que només el darrer segle i mig, alguns filòsofs han començat a desarmar aquest marc del temps aristotèlic. En aquest sentit, són imprescindibles les aportacions d'autors com Schelling, que defensa un concepte orgànic del temps, en el qual cadascú posseeix un temps intern propi; 0 els autors que recuperen la concepció antiga de temps circular. Entre aquests últims, destaquen Hegel, que afegeix a la idea de temps com a moviment una lògica cíclica històrica amb la noció de dialèctica, Heidegger o Nietzsche, que desenvolupa la idea de l'etern retorn.

Aquest treball sobre el temps es fa de manera molt conscient en la dramatúrgia de La Conquesta: «És una cosa nostra, això de plegar el temps -diu Fernández Giua-, perquè el Ilenguatge teatral et permet superposar capes de coneixement. Aquest gruix d'informació ens permet unificar el temps. Veure una persona, però veure la imatge collectiva, i veure el passat d'aquella persona i com es representa en el futur. Treballem molt sobre la idea d'acumulació. I anem construint les escenes perquè hi arribi un moment d'una connexió especialment forta, una emoció que es destapa.» 


\section{artnodes}

https://artnodes.uoc.edu

El temps circular: noves maneres de narrar l'experiència. La dramatúrgia acumulativa de La Conquesta del Pol Sud

Tots dos estan d'acord que tota la seva construcció de la narració va encaminada cap a una transformació col·lectiva, cap a una mena de catarsi, perquè és «una condició del teatre» i perquè creuen que «'emoció et fa conèixer.»A les seves obres, hi ha «una part analítica i un mecanisme molt potent d'empatia, i és entre aquestes dues coses en equilibri que l'espectador es fa un coneixement que també és emocional». Escènicament, ideen dispositius que ho transmeten, com les persianes del muntatge de Claudia, que gradualment van modificant la inclinació i que mostren i oculten al mateix temps, el contrari d'una etapa superada i nítida. Tampoc a les altres dues obres de la trilogia no hi ha trencament, sinó continuïtat fluïda.

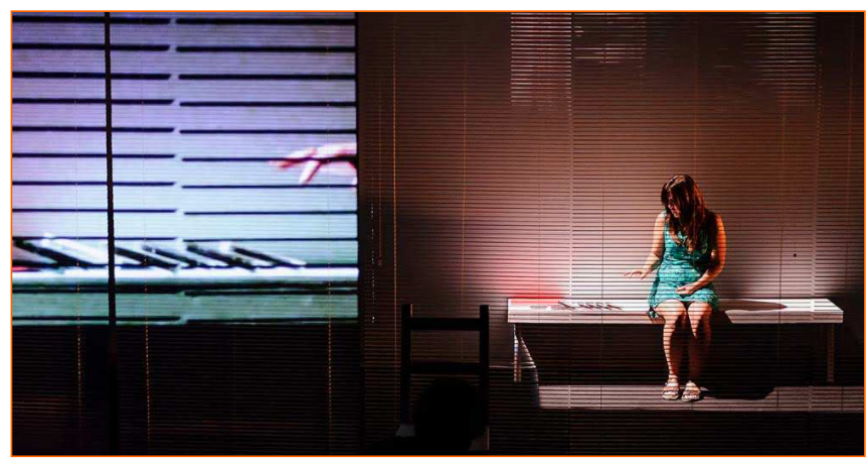

Figura 3. Les persianes del muntatge de Claudia, que mostren i oculten alhora (2019) Font: https://www.laconquesta.com/proyectos/trilogia-claudia

\section{Conclusions}

A la trilogia de La Conquesta, doncs, apreciem un evident abandonament de la seqüencialitat convencional de l'escena, que funciona emocionalment i analíticament. En els seus muntatges, apreciem una circularitat més harmònica. No hi ha un passat, un present i un futur que s'oposin radicalment, sinó que tot està contingut en una unitat, això és el que fa possible la reconciliació i la reparació. Hi trobem un procés, com en les nocions orientals d'arrel taoista, del yin i el yang: les identitats, per exemple, estan en transició, i no cristal/litzades, en termes dels mateixos dramaturgs. Això es veu molt clarament en l'evolució de les tres protagonistes sobre l'escenari. En aquesta temporalitat, busquen i troben el canvi sense ruptura: hi ha un afebliment de les estructures de sentit, que és el que fa possible la transformació, que no arriba per mitjà d'esdeveniments epifenòmics, sinó per la concurrència i l'acumulació de circumstàncies que expliquen moments de revelació i de connexió amb els públics.

Després de l'anàlisi del mètode de construcció d'imaginaris narratius de La Conquesta, hem confirmat que les propostes d'una temporalitat alternativa al «temps vulgar» són eficaces per imaginar nous espais narratius que ens permetin construir-nos des de l'empatia, individualment i col·lectivament. Així, tal com mostrem a la taula, el temps no s'entén com a sinònim de moviment, sinó com un procés, en el qual subjau una immanència del relat. A més, en aquesta concepció del temps narrat, el subjecte no és un cos violentat per les narracions hegemòniques, sinó que és dipositari d'una força que neix de la interacció i que transmet les narracions col·lectives.

Per això, les protagonistes i els públics no senten una dislocació en la construcció de la identitat individual i col-lectiva, perquè no estan sotmesos a cap acceleració, sinó a una transformació orgànica. Precisament per això, els subjectes no tenen valor per la seva mera presència en un esdeveniment artificialment construït pel discurs hegemònic, sinó per la seva capacitat de fer, de modificar els imaginaris, en un moment determinat i en unes circumstàncies concretes. L'exemple de La Conquesta demostra com sí que podem narrar sense fer servir el trencament i la ruptura entre el passat, el present i el futur, de manera que la memòria s'activa com a eina reparadora de les comunitats, fet que fa possible una imaginació amb potencial emancipador.

\begin{tabular}{|c|c|c|}
\hline \multirow{2}{*}{ PRIMER PLEC: COM PERCEBEM EL TEMPS? } & TEMPS VULGAR & TEMPS CIRCULAR \\
\hline \multirow{4}{*}{ SEGON PLEC: COM NARREM L'EXPERIÈNCIA? } & Temps lineal & Temps com a procés \\
\cline { 2 - 3 } & Moviment (progrés) & Constància (embolcall) \\
\cline { 2 - 3 } & Cos (violència) & Energia (interrelació) \\
\cline { 2 - 3 } & Transmissions & Correlacions \\
\hline \multirow{2}{*}{ TERCER PLEC: COM FEM SERVIR EL LLENGUATGE? } & Caiguda (vertigen) & Transformació (equilibri) \\
\cline { 2 - 3 } & Ser (inamobilitat) & Fer (capacitat) \\
\cline { 2 - 3 } & Ruptura (crisi) & Canvi (debilitament) \\
\cline { 2 - 3 } & En seqüències & En translació \\
\cline { 2 - 3 } & Esdeveniment (escena) & Moment (circumstància) \\
\cline { 2 - 3 } & Conjugació & Acumulació \\
\cline { 2 - 3 } & Oposició (diferència) & Transició (diversitat) \\
\hline \multirow{2}{*}{} & Greuge & Reparació \\
\hline
\end{tabular}

Taula 2. Comparativa conceptual entre temps vulgar i temps circular

Font: elaboració pròpia 


\section{Referències bibliogràfiques}

Avanessian, Armen, Reis, Mauro. «Introducción». W.AA. Aceleracionismo. Estrategias para una Transición hacia el Postcapitalismo, 9-32. Buenos Aires: Caja Negra Editora, 2019.

Berardi, Franco «Bifo». «El Aceleracionismo Cuestionado desde el Punto de Vista del Cuerpo». W.AA. Aceleracionismo. Estrategias para una Transición hacia el Postcapitalismo, 69-76. Buenos Aires: Caja Negra Editora, 2019-a.

Berardi, Franco «Bifo». Futurabilidad. La Era de la Impotencia y el Horizonte de la Posibilidad. Buenos Aires: Caja Negra Editora, 2019-b.

Bernat, Roger, "Com trenquem la quarta paret», entrevistat per Albert Lladó. Escola de pensament, Teatre Lliure, 28 de juny, 2021, vídeo, 1:20:46. https://www.youtube.com/watch?v=gFsJXzsxAEc.

Borrat, Héctor. El Periódico, Actor Político. Barcelona: Editorial Gustavo Gili, 1989.

Derrida, Jacques. Espectros de Marx. El Estado de la Deuda, el Trabajo del Duelo y la Nueva Internacional. Madrid: Editorial Trotta, 1995.

Derrida, Jacques. Tiempo y Presencia. Santiago de Chile: Universidad Diego Portales, 2005. (Treball original publicat el 1972).

Duch, Lluís. «Antropologia de la Comunicació». Anàlisi, no. 29 (2002): 21-41. https://ddd.uab.cat/pub/analisi/02112175n29/02112175n29p21.pdf.

Duch, Lluís. Vida Cotidiana y Velocidad. Barcelona: Herder, 2019.

Duch, Lluís, Chillón, Albert. Un ser de mediaciones. Barcelona: Herder, 2012. D0l: https://doi.org/10.2307/j.ctvt7x7xh.

Fisher, Mark. Realismo Capitalista: ¿No Hay Alternativa?. Buenos Aires: Caja Negra Editora, 2018.
Fukuyama, Francis. El Fin de la Historia y el Último Hombre. Barcelona: Planeta, 1992.

Garcés, Marina. Filosofia inacabada. Barcelona: Galaxia Gutenberg, 2014.

Gayà, Catalina, Seró, Laia. Ulisses era una dona. Barcelona: Museu Martítim de Barcelona, 2021. https://www.mmb.cat/wp-content/ uploads/2021/05/Ulisses-era-una-dona.pdf

Heidegger, Martin. El Ser y el Tiempo. México: Fondo de Cultura Económica, 1986. (Treball original publicat el 1927).

Jullien, François. Del «Tiempo». Madrid: Arena Libros, 2005.

Lynch, Enrique. La Lección de Sheherezade. Barcelona: Anagrama, 2006. (Treball original publicat el 1987).

Ricoeur, Paul. «Narratividad, Fenomenología y Hermenéutica». Anàlisi, no. 25 (2000): 189-207. https://ddd.uab.cat/pub/analisi/02112175n25/02112175n25p189.pdf.

Ricoeur, Paul. Tiempo y Narración III. El Tiempo Narrado. Mèxic: Siglo XXI, 1996. (Treball original publicat el 1985).

Vidal Castell, David. El Malson de Chandos. Bellaterra (Cerdanyola del Vallès): Aldea Global, 2005.

Virilio, Paul. Velocidad y Política. Buenos Aires: La marca editora, 2006. (Treball original publicat el 1977).

Zafra, Remedios. Frágiles. Barcelona: Anagrama, 2021.

Williams, Alex, Srnicek, Nick. «Manifiesto por una Política Aceleracionista». W.AA. Aceleracionismo. Estrategias para una Transición hacia el Postcapitalismo, 33-48. Buenos Aires: Caja Negra Editora, 2019. 


\section{artnodes}

\section{CV}

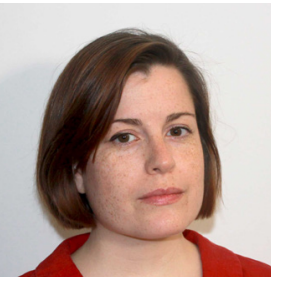

\section{Cristina Garde Cano}

Doctoranda del Departament de Mitjans, Comunicació i Cultura de la Facultat de Comunicació, Universitat Autònoma de Barcelona.

cristina.garde@gmail.com

Doctoranda del Departament de Mitjans, Comunicació i Cultura (UAB). És llicenciada en Periodisme per la UAB (2007) i graduada en Arts i Disseny per l'Escola Massana (2014). Així mateix, ha cursat el Postgrau de Disseny de Publicacions Digitals a EINA (2014). Ha treballat com a periodista especialitzada en societat, infografia i disseny gràfic a El País, El Periódico i Nació Digital i com a corresponsal a Brussel-les de l'Agència Catalana de Notícies (ACN). Ha rebut els premis Civisme 2018 i 2019 per dues sèries de reportatges i ha estat reconeguda amb el premi Montserrat Roig 2020 per la seva trajectòria com a coordinadora de Social.cat, el diari digital de l'acció social a Catalunya.

https://orcid.org/0000-0002-8700-9686

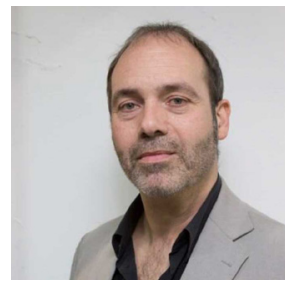

\section{David Vidal Castell}

Director del Departament de Mitjans, Comunicació i Cultura de la Universitat Autònoma de Barcelona.

david.vidal@uab.cat

Professor titular de Periodisme Cultural i de Periodisme Literari a la Facultat de Ciències de la Comunicació de la UAB, doctor amb la tesi Alteritat $i$ presència (2002), ha guanyat els premis del Consell de l'Audiovisual de Catalunya per El malson de Chandos (Aldea Global, 2005), Lleida de Narrativa (La fulla a punt de caure, 2007) i el premi Gaudí pel guió del documental Petitet (2019). Ha estat codirector de l'Arts Santa Mònica, i responsable del projecte MèdiaQuiosc (2010-2012), i comissari de diverses exposicions (la darrera, Corrupció! Revolta ètica, el 2019, al Palau Robert). Crític literari del diari Ara i col-laborador de diversos mitjans com a analista, actualment és director del Departament de Mitjans, Comunicació i Cultura i del màster de Periodisme Literari, Comunicació i Humanitats de la UAB.

https://orcid.org/0000-0002-8178-6580

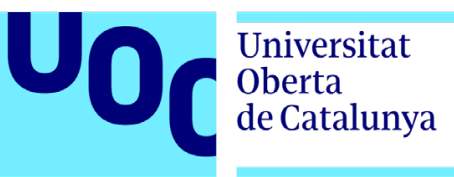

